\title{
The Experimental Study on Effects of Height and Hold up on performance of Vertical Gas-Liquid Separator using Amin Contactor Tower
}

\author{
Iman Naderipour ${ }^{1, *}$, Jamshid khorshidi ${ }^{2}$ \\ ${ }^{1}$ Ph.D. Student in Mechanical Engineering, Sarkhoun and Qeshm Gas Treating Company (SQGC), Iran, \\ Iman_naderipour@yahoo.com \\ 2 Professor in Chemical Engineering, Faulty of Science and Technology. Hormozgan University, Iran,
}

JKhorshidi@gmail.com

\begin{abstract}
In present research, first the treatment of flow in designed vertical gas-liquid separator and Amin contactor tower at refinery in order to reduce of liquid percent was simulated. In order to simulation was used three dimension model with finite volume method numerically. Then separator and contactor tower has been modeled three dimensional and for droplet tracking in continuous phase has been used discrete phase model (DPM) with turbulence RNG $k-E$ model. Also the gambit software is used for three dimension designs and fluent is used for solution governing equations of flow field. After simulation, the governing model of separator and contactor tower, fluid flow, the effect of growing of liquid droplet, droplet settling length (disengagement time) was studied. After analysis and compare behavior of flow in separator and tower, the results of simulation compared with experimental results at sweetening unit in Sarkhoun and Qeshm gas treating company that has 95\% compatibility. The simulation results has shown that TOTAL method has more compatibility with relation to other methods so that one of effective parameters in improvement of separation process is growing of liquid droplets and separation factor depend on that, also more disengagement time causes increase hold up time and finally growing of liquid droplets. Additionally according to younger's comment gasliquid separators can applied in horizontal or vertical status so that he founded if $L / D$ be 1.7 to 3.6 , the separators should be used vertically also Branan has proved that if $L / D>5$, a horizontal separator should be used. The results of research are shown that in special conditions with $L / D>6.5$ can apply vertical separator. Finally experimental data has shown that the settling length can be $36 \mathrm{ft}$ (11m) that separation works well and according to Schiman this length should be $0.75 \mathrm{D}$ or a minimum $12 \mathrm{in}(0.305 \mathrm{~m})$ whereas Gerunda recommends a leng th equal to the diameter or a minimum of $3 \mathrm{ft}(0.914 \mathrm{~m})$ that present result is new recommendation.
\end{abstract}

Keywords: Gas-liquid separator, Amin contactor tower, Simulation, discrete phase model (DPM), Experimental data. 


\section{Introduction}

$\mathrm{P}$ roduced liquid that produce from wells is multiphase (two phases as oil, gas and sometimes three phase as oil, gas and water or oil, gas and sand). In addition to each one of phases are separable by borders between them. Pressure and temperature conditions of a material describe phase state (solid, liquid and vapor or gas).Usually one of phases consider the purpose of more scape element and other phase with less scape Thus, must for consumption of each phase separate them by the certain method. Separation in variety vessels does with especial design. The gases content compounds that in meeting of water area produces acid solutions and more contain hydrogen sulfide, carbon dioxide, sulfide carbonyl (COS), disulfide carbon (CS2) and mercaptanes (R-SH). The gases contain these component are "Soar Gas" and the process does for separate of these components, it called "Gas Sweetening". When these combines are poisoning that feed contain vapor or there is condensation of vapor or other combined that produce acid with $\mathrm{H} 2 \mathrm{~S}$ and $\mathrm{CO} 2$. When acid combined percent is more than export or consumption allowable limit must apply sweetening process for separate of these combines. [1] Gas-liquid separation processes used in variety industrial place are based on "Gravity Settling", "Impingement" and "Centrifugation", mechanisms. Sometimes, they apply either one or a combination of them and also "Filtration" can apply in this field. As for a general rule, mechanical separation happened when the phases are not miscible and have different densities. Types of mechanical separation can be classified as momentum, gravity and filtration [2]. Vapor-Liquid separators are common types of processing equipment that use vertically, horizontally and spherically. The vertical separators apply for liquid separation from mixture with high gas-oil mass ratio (LIQ $<10-20 \%$ ) or short liquid hold up time. Contactor surface of gas and liquid in vertical separators in compare with horizontally is less [3]. Improvements of computational fluid dynamics (CFD) has been provide the basis for further insight into approach in dynamic of multiphase flows. Currently, there are two approaches for numerical calculate of multiphase flows: the Euler-Lagrange and the Euler-Euler approaches. In the Euler-Lagrange the fluid phase is treated as a continuum by solving the time-averaged Navier-Stokes equations, while the dispersed phase is solved by tracking a large number of bubbles, droplets or particles through the calculated flow field so that in the EulerEuler approach, the different phases are treated mathematically as interpenetrating continua. Since the volume of a phase cannot be occupied by the other assumed to be continuous functions of space and time and their sum is equal to one. Conservation equations for each phase are derived to obtain a set of equations, which have similar structure for all phases. Discrete phase model (DPM) follows the Euler-Lagrange approach, while the volume of fluid (VOF) model, the mixture model, and the Eulerian model follow the Euler-Euler approach. [4] This regard (Sirazi et al., 1996) has simulated a cylindrical gas-liquid cyclone numericaly [5]. Annaland and Kuipers (2005) simulated gasliquid-solid by combined front tracking and (DPM) [6]. (Juoyan et al., 2005) have been studied performance of helical gas-liquid separator numerically and practically [7]. (Luchang et al., 2007) simulated gas hold up in motion vessel by DPM [8].Also (Nirschl et al., 2008) simulated treat of particle at a centrifugal vessel with (DPM) and (VOF) models numerically [9]. (Schepper et al., 2008) modeling of gas-liquid regime by BAKER chart and comparing experimental dada shown that in this method was used (VOF) model [10]. (Olsem and Cloete, 2009) analyzed high gas rate with coupling (DPM) and (VOF) and shown that lift force do not have any effect on higher gas rate [11]. (Haario and Patel, 2010) simulated twophase and three-phase flows in a reactor [12]. Also (Vinay Mahajan, 2010) studied hydrodynamic and mass transfer in bubble column by mixture model [13]. (Holger, 2011) simulated complete spray with couple (DPM) and (VOF) models [14]. Finally (Khorshidi and 
Naderipour, 2012) simulated a vertical gas-liquid separator by (DPM) model [15]. Due to reduction of $\mathrm{H}_{2} \mathrm{~S}$ from wells outlet gas, sweetening unit was out of service for a long period of time and outlet gas fraught with liquid in separation unit, also in order to optimum use of instruments and devices in this unit, using Amin contactor tower the as a separator has been recommended in R\&D unit of Sarkhoun and Qeshm gas treating company. The ultimate goal of this research is to examine the possibility of using of Amine contactor tower as a vertical gasliquid separator in order to reduce liquid in outlet of separation unit and carry it to the dew point setting unit for dehydration. This regard after design of requirement separator in outlet of separation unit by Khorshidi and Naderipour, treat of fluid flow was studied by solving of governing equations in separator and contactor tower flow.

\section{Model Description}

If consider a liquid droplet with diameter $\mathrm{dp}$ that in settling area by gravity force When the net gravity force, given by Eq. 1 to 6, also figure 1 is shown forces on liquid droplet in gas stream.

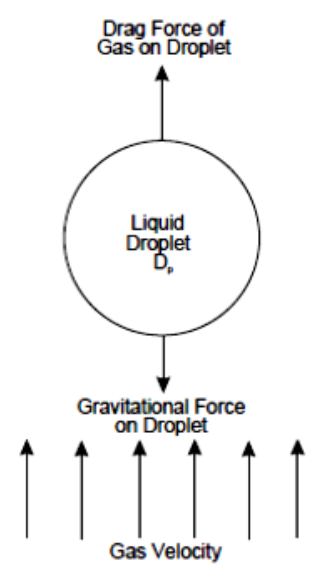

Figure 1: Forces on Liquid Droplet in Gas Stream.

Forces on droplet are:

-Gravitational force given by Eq.1,

$F_{g}=\frac{\pi}{6} \cdot d_{p}^{3} \cdot\left(\rho_{l}-\rho_{v}\right) \cdot g$

-Balance the drag force, given by Eq. 2,
$F_{d}=\frac{\pi}{8} \cdot U_{T}^{2} d_{p}^{2} \cdot \rho_{v} \cdot C_{d}$

The heavier liquid droplets will settle at a constant terminal velocity, UT Equating Eqs.1 and 2 results in,

$U_{T}=\sqrt{\frac{4 \cdot g \cdot d_{p}\left(\rho_{l}-\rho_{v}\right)}{3 \cdot C_{d} \cdot \rho_{v^{\prime}}}}$

Hence, as long as $\mathrm{UV}_{\mathrm{v}}<\mathrm{UT}_{\mathrm{T}}$, the liquid droplets will settle out. Typically, $U_{v}$, is set between 0.75 $\mathrm{U}_{\mathrm{T}}$ and $\mathrm{U}_{\mathrm{T}}$ Eq. 3 can be rearranged as Eq. 4, a Sauders-Brown type equation (1):

$U_{T}=K \sqrt{\frac{\left(\rho_{l}-\rho_{v}\right)}{\rho_{v^{\prime}}}}$

Where $\mathrm{K}$ is separation factor and given by Eq.5,

$K=\sqrt{\frac{4 \cdot g \cdot d_{p}}{3 \cdot C_{d}}}$

Practically, very small droplets cannot be separated by gravity alone. These droplets are coalesced to from larger droplets which will settle by gravity. Coalescing devices in separators force the gas to follow a tortuous path and the momentum of the droplets cause them to collide with other droplets or the coalescing device, forming larger droplet diameter is not adequately predictable so the $\mathrm{K}$ values for mist eliminators are typically empirical. In this paper in order to simulation of floe field, were applied gas-liquid regime, discrete phase model (DPM) for study of dispersed phase (droplets) treat and fluent software. According to table 3, Duo to volume fraction of dispersed phase is less $10 \%$ of inlet fluid, was used DPM method [15].

\section{Geometry}

Generated geometry was modeled for designed vertical separator by Khorshidi and Naderipour with use gambit software three dimensionally $[15,16]$ and shown in figure 2 . Also for tower geometry was used documents and maps of tower in sweetening unit [17]. The geometry of vertical separator and contactor tower shown in Table 1, 


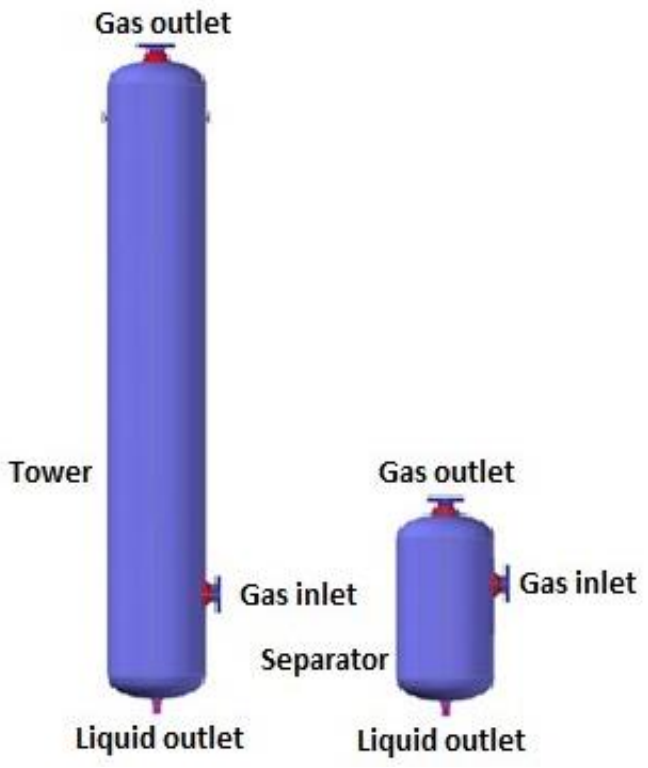

Figure 2: Vertical gas-liquid separator and contact tower.

Tabela 1: Geometry of vertical separator and contactor tower

\begin{tabular}{lll}
\hline $\begin{array}{l}\text { Dimensions } \\
\text { [mm] }\end{array}$ & Separator & Tower \\
\hline Diameter & 2450 & 2450 \\
Height & 3000 & 15640 \\
Gas Inlet & 355.6 & 355.6 \\
Gas Outlet & 355.6 & 355.6 \\
Liquid Outlet & 152.4 & 152.4 \\
\hline
\end{tabular}

\section{Mesh Generation}

In this research in order to study of mesh effect on results and choosing optimum mesh, the change of velocity on a stream line direction height separator and tower was examined. Thus, first are generated meshes for separator with 64372 cells, then by increasing numbers of cells, change of velocity has been selected as mesh effect criteria. With increasing numbers of mesh from 13645 to 136453 cells, the change of velocity is little and overall of this variable on compare with number of chancing element has been bit more. In this section, meshes with 65372 cells duo to high resolution of calculate and optimum time as optimum mesh was selected. Three variety views of these mesh generation (that is tetrahedral type shown in figure $3[16,17]$.
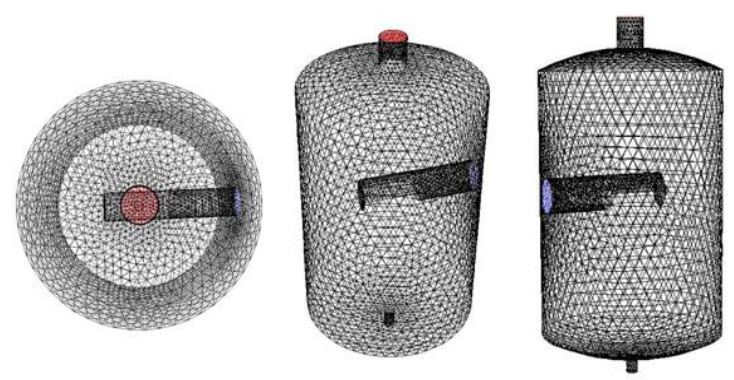

Figure 3: Mesh generation of vertical separator.
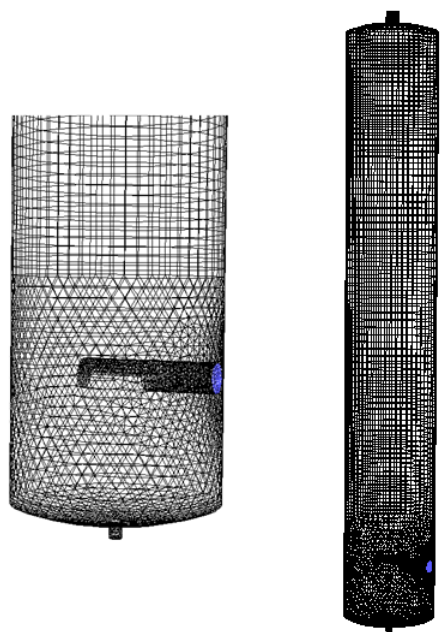

Figure 4: Mesh generation of Amin contact tower.

Also in modeling of contactor tower was shown that with increasing number of cells from 121365 to 445321, calculated overall of velocity aren't attention able except gas inlet and outlet. Although difference of velocity in meshes with 273278 cells on compare with meshes with 121365 is negligible, thus this model the purpose of optimum tetrahedral mesh generation was selected. Figure 4 is shown mesh generation of contactor tower. Note that in bottom of tower duo to irregular geometry was applied irregular mesh generation and after that regular mesh generation was swept.

\section{Boundary Condition}

Boundary condition of walls for continues phase were selected so that all of lateral surface and all of surface that aren't gas inlet and outlet as No Slip Condition and boundary conditions will be $u=v=w=0$. Boundary condition for continues phase is velocity in gas inlet surface 
that is equal to $8 \mathrm{~m} / \mathrm{s}$. Also for gas outlet was considered outlet pressure. Totally duo to boundary conditions is absolute geometry and depends on operation conditions therefore there aren't any change into separator and contactor tower, the boundary conditions will can satisfy problem. For start of numerical solution, must consider initial conditions. These conditions is contain initial overall of velocity, pressure, temperature fields into separator and tower that here $\mathrm{u}=\mathrm{v}=\mathrm{w}=\mathrm{P}=\mathrm{T}=0$ were selected. While a droplet arrive to physical border, must apply boundary conditions of discrete phase that Trap was defined [4, 17].

\section{Solving of Flow Field}

Fluid flow for continues phase steady, three dimensional, compressible, turbulent was considered. Also for solver pressure-based with implicit formulation and for turbulent modeling RNG k- $\varepsilon$ was applied. The governing equation of dispersed phase flow given by Eq.7, [4, 16]

$$
\begin{aligned}
& \frac{d u_{p}}{d t}=F_{D}\left(u-u_{p}\right)+\frac{g_{x}\left(\rho_{p}-\rho\right)}{\rho_{p}}+F_{x} \\
& F_{D}=\frac{18 \mu}{\rho_{p} d_{p}^{2}} \frac{C_{D} R_{e}}{24}
\end{aligned}
$$

Re is Reynolds number that given by Eq.8,

$R_{e}=\frac{\rho . d_{p}\left|u_{p}-u\right|}{\mu}$

Additionally, the equation 7 convert by convert functions of software to cylindrical ordinate in $\mathrm{r}, \mathrm{z}$ direction. Also for liquid sprays, an appropriate representation of the droplet size distribution is the Rosin- Rammler expression. The complete range of sizes is divided into an adequate number of discrete intervals, each represented by a mean diameter for which trajectory calculations are performed. The size distribution is of the Rosin-Rammler type, the mass fraction of droplets of diameter greater than $\mathrm{d}$ is given by Eq.9,

$$
Y_{d}=e^{-(d / \bar{d})^{n}}
$$

In order to simulation, need to operation conditions and properties of inlet feed that these cases were obtained by Khorshidi and Naderipour and are shown in table 2 and 3. [15, 17].

\section{Results}

After solving of field fluid flow into separator and contact tower, effect of growing of droplets, effect of disengagement long in separation process was studied.
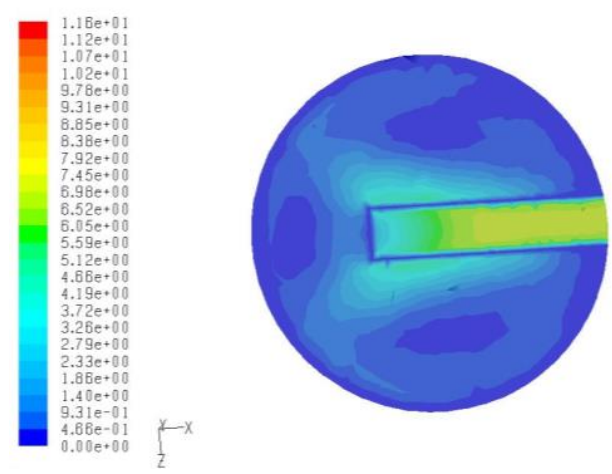

Figure 5: Velocity contours in separator from top view.

Figure 5, contours of velocity and figure 6 vectors of velocity in inlet transient section from top view are shown that these are same together. Also in these view effect of inlet diverter is shown. One of properties of stagnation point is that because of impact and change of trace flow, the momentum of flow decreases and will help to liquid gather and separation, [14, 15 and 17].
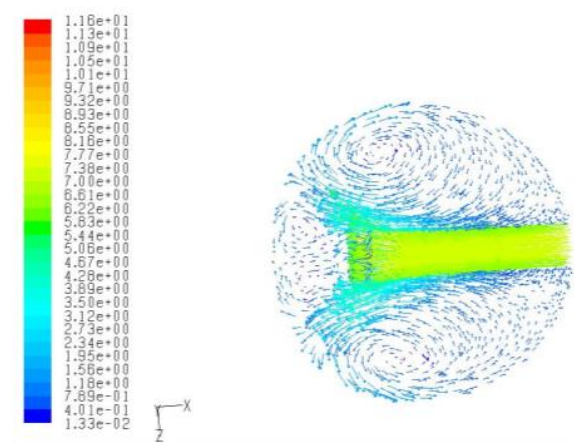

Figure 6: Velocity vectors in separator from top view.

Figures 7 and 8 shown that duo to collision and divert of flow, eddies generate around diverter (nozzle) and bottom of vessel. Formation of these eddies by increasing hold up of particle in separator and tower helps to 
growing of droplets, since sudden divert is one of principal reason to steady of eddies.
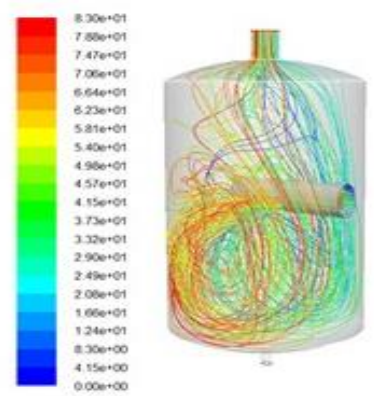

Figure 7: Stream line of fluid flow in

separator Figure 8 shown stream line of particle from feed inlet to gas outlet continuously. The large of separation do by interference stream line of particles and collision and at last causes growing of droplets. Also figure 7 and 8 in order are shown trace of injected particles with 45 microns in separator and contact tower.
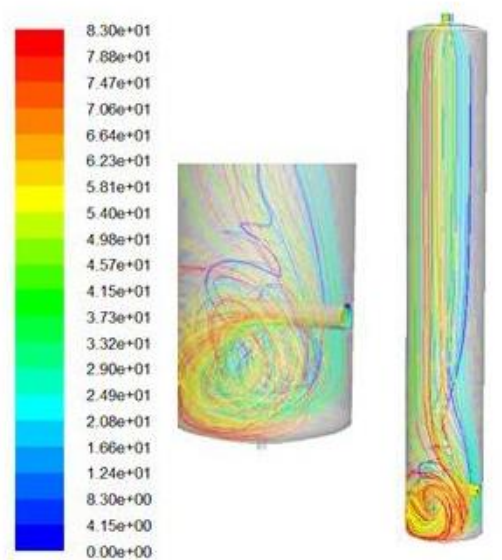

Figure 8: Stream line of fluid flow in contactor tower.
In order to study effect of growing of liquid droplets, in order droplets with 40, 120 and 150 microns has been injected into separator and tower. The growing trend of droplets is so that maximum diameter of droplets in tower is worthy larger than similar overall in separator that it is because of more hold up time of droplets in tower as compared to separator. Maximum diameter of droplets into separator and contact tower shown in figure 9,

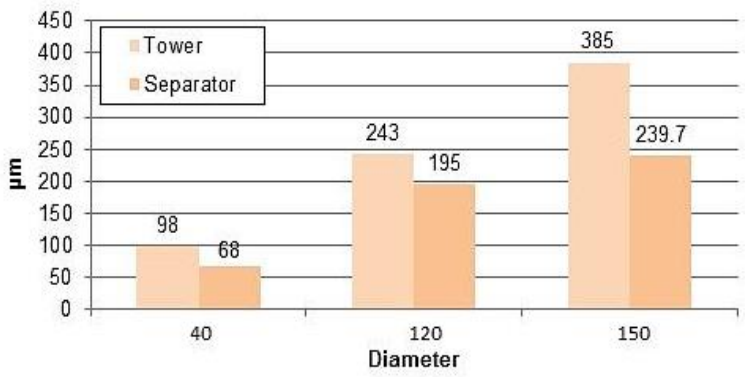

Figure 9: Maximum growing of droplets

As for table 3, inlet feed is content two phase (gas-liquid) and also as mentioned before if liquid - gas ratio is less than (i.e. LIQ < 10-20\%) volume fraction, should be use vertical separator, therefore can sure that design was done goodly, so table 4 shown that outlet fluid from separator is only gas that it shows liquid phase was separated from feed fluid.

Table 2: Operation condition is measured in Sarkhoun \& Qeshm refinery

\begin{tabular}{ccccc}
\hline Conditions & Unit & Overall & Vapor Phase & Liquid Phase \\
\hline Temperature & {$\left[\mathrm{C}^{\circ}\right]$} & 53 & 53 & $\mathbf{5 3}$ \\
\hline Pressure & {$[\mathrm{KPa}]$} & 6771 & 6771 & $\mathbf{6 7 7 1}$ \\
\hline Molar Flow & {$[\mathrm{kgmole} / \mathrm{hr}]$} & 8411 & 8194 & $\mathbf{2 1 7 . 5}$ \\
\hline Mass Flow & {$[\mathrm{kg} / \mathrm{hr}]$} & $1.789 \mathrm{e}+005$ & $1.654 \mathrm{e}+005$ & $\mathbf{1 . 3 5 3 e + 0 0 4}$ \\
\hline
\end{tabular}

Table 3: Properties of inlet fluid

\begin{tabular}{ccccc}
\hline Properties & Unit & Overall & Vapor Phase & Liquid Phase \\
\hline $\boldsymbol{\rho}$ & {$[\mathrm{kg} / \mathrm{m} 3]$} & 62.34 & 58.13 & 551.3 \\
\hline $\mathbf{C p}$ & $\begin{array}{c}{[\mathrm{kJ} / \mathrm{kgmole}-} \\
\mathrm{c}]\end{array}$ & 53.75 & 51.04 & 155.8 \\
& {$[\mathrm{~kg} / \mathrm{ms}]$} & --- & $1.436 \mathrm{e}-002$ & 0.1470 \\
\hline $\boldsymbol{\mu}$ & &
\end{tabular}




\begin{tabular}{ccccc}
\hline $\mathbf{Q}$ & {$[\mathrm{m} 3 / \mathrm{hr}]$} & 2870 & 2845 & 24.54 \\
\hline $\mathbf{Z}$ Factor & --- & --- & 0.8670 & 0.2818 \\
\hline $\boldsymbol{\sigma}$ & {$[\mathrm{Cs}]$} & --- & 0.2470 & 0.2667 \\
\hline $\mathbf{W}$ & {$[\mathrm{kg} / \mathrm{hr}]$} & $1.789 \mathrm{e}+0$ & $1.654 \mathrm{e}+00$ & $1.353 \mathrm{e}+00$ \\
& & 05 & 5 & 4 \\
\hline $\begin{array}{c}\text { Phase Fraction [molar } \\
\text { Basis] }\end{array}$ & --- & 0.9741 & 0.9741 & 0.0259 \\
\hline Phase Fraction [vol.asis] & --- & 0.9536 & 0.9536 & 0.0464 \\
\hline
\end{tabular}

Table 4: Outlet properties of separator

\begin{tabular}{cccc}
\hline Properties & Unit & Overall & Vapor Phase \\
\hline $\boldsymbol{\rho}$ & {$[\mathrm{kg} / \mathrm{m} 3]$} & 51.18 & 51.18 \\
\hline $\mathbf{C}$ & {$[\mathrm{kJ} / \mathrm{kgmole}-\mathrm{c}]$} & 46.78 & 46.78 \\
\hline $\boldsymbol{\mu}$ & {$[\mathrm{kg} / \mathrm{ms}]$} & $1.419 \mathrm{e}-002$ & $1.419 \mathrm{e}-002$ \\
\hline $\mathbf{Q}$ & {$[\mathrm{m} 3 / \mathrm{hr}]$} & 3496 & 3496 \\
\hline $\mathbf{Z}$ Factor & --- & 0.8958 & 0.8958 \\
\hline $\boldsymbol{\sigma}$ & {$[\mathrm{Cs}]$} & 0.2772 & 0.2772 \\
\hline $\mathbf{W}$ & {$[\mathrm{kg} / \mathrm{hr}]$} & $1.789 \mathrm{e}+005$ & $1.789 \mathrm{e}+005$ \\
\hline Phase Fraction [molar Basis] & --- & 1.00 & 1.00 \\
\hline Phase Fraction [vol.asis] & --- & -- & 1.00 \\
\hline
\end{tabular}

Table 5: Outlet properties of $13 \mathrm{~A}$ contactor tower

\begin{tabular}{cccc}
\hline Properties & Unit & Overall & Vapor Phase \\
\hline $\boldsymbol{\rho}$ & {$[\mathrm{kg} / \mathrm{m} 3]$} & 51.71 & 51.71 \\
\hline $\mathbf{C p}$ & {$[\mathrm{kJ} / \mathrm{kgmole}-\mathrm{c}]$} & 47.12 & 47.12 \\
\hline $\boldsymbol{\mu}$ & {$[\mathrm{kg} / \mathrm{ms}]$} & $1.425 \mathrm{e}-002$ & $1.425 \mathrm{e}-002$ \\
\hline $\mathbf{Q}$ & {$[\mathrm{m} 3 / \mathrm{hr}]$} & 3460 & 3460 \\
\hline $\mathbf{Z ~ F a c t o r}$ & -- & 0.8949 & 0.8949 \\
\hline $\boldsymbol{\sigma}$ & {$[\mathrm{Cs}]$} & 0.2756 & 0.2756 \\
\hline $\mathbf{W}$ & {$[\mathrm{kg} / \mathrm{hr}]$} & $1.789 \mathrm{e}+005$ & $1.789 \mathrm{e}+005$ \\
\hline Phase Fraction [molar Basis] & --- & 1.00 & 1.00 \\
\hline Phase Fraction [vol.asis] & --- & -- & 1.00 \\
\hline
\end{tabular}

Table 6: Outlet properties of $13 \mathrm{~B}$ contactor tower

\begin{tabular}{cccc}
\hline Properties & Unit & Overall & Vapor Phase \\
\hline $\boldsymbol{\rho}$ & {$[\mathrm{kg} / \mathrm{m} 3]$} & 52.33 & 52.33 \\
\hline $\mathbf{C p}$ & {$[\mathrm{kJ} / \mathrm{kgmole}-\mathrm{c}]$} & 47.57 & 47.57 \\
\hline $\boldsymbol{\mu}$ & {$[\mathrm{kg} / \mathrm{ms}]$} & $1.428 \mathrm{e}-002$ & $1.428 \mathrm{e}-002$ \\
\hline $\mathbf{Q}$ & {$[\mathrm{m} 3 / \mathrm{hr}]$} & 3419 & 3419 \\
\hline $\mathbf{Z}$ Factor & --- & 0.8926 & 0.8926 \\
\hline $\boldsymbol{\sigma}$ & {$[\mathrm{Cs}]$} & 0.2730 & 0.2730 \\
\hline $\mathbf{W}$ & {$[\mathrm{kg} / \mathrm{hr}]$} & $1.789 \mathrm{e}+005$ & $1.789 \mathrm{e}+005$ \\
\hline Phase Fraction [molar Basis] & --- & 1.00 & 1.00 \\
\hline Phase Fraction [vol.asis] & --- & -- & 1.00 \\
\hline
\end{tabular}


Table 7: Outlet properties of $13 \mathrm{C}$ contactor tower

\begin{tabular}{cccc}
\hline Properties & Unit & Overall & Vapor Phase \\
\hline $\boldsymbol{\rho}$ & {$[\mathrm{kg} / \mathrm{m} 3]$} & 57.09 & 57.09 \\
\hline $\mathbf{C}$ & {$[\mathrm{kJ} / \mathrm{kgmole}-\mathrm{c}]$} & 51.04 & 51.04 \\
\hline $\boldsymbol{\mu}$ & {$[\mathrm{kg} / \mathrm{ms}]$} & $1.454 \mathrm{e}-002$ & $1.454 \mathrm{e}-002$ \\
\hline $\mathbf{Q}$ & {$[\mathrm{m} 3 / \mathrm{hr}]$} & 3134 & 3134 \\
\hline $\mathbf{Z}$ Factor & --- & 0.8747 & 0.8747 \\
\hline $\boldsymbol{\sigma}$ & {$[\mathrm{Cs}]$} & 0.2546 & 0.2546 \\
\hline $\mathbf{W}$ & {$[\mathrm{kg} / \mathrm{hr}]$} & $1.789 \mathrm{e}+005$ & $1.789 \mathrm{e}+005$ \\
\hline Phase Fraction [molar Basis] & --- & 1.00 & 1.00 \\
\hline Phase Fraction [vol.asis] & --- & --- & 1.00 \\
\hline
\end{tabular}

Table 8: Outlet properties of contactor tower

\begin{tabular}{cccc}
\hline Properties & Unit & Overall & Vapor Phase \\
\hline $\boldsymbol{\rho}$ & {$[\mathrm{kg} / \mathrm{m} 3]$} & 54.54 & 54.54 \\
\hline $\mathbf{p}$ & {$[\mathrm{kJ} / \mathrm{kgmole}-\mathrm{c}]$} & 48.40 & 48.40 \\
\hline $\boldsymbol{\mu}$ & {$[\mathrm{kg} / \mathrm{ms}]$} & $1.417 \mathrm{e}-002$ & $1.417 \mathrm{e}-002$ \\
\hline $\mathbf{Q}$ & {$[\mathrm{m} 3 / \mathrm{hr}]$} & 3280 & 3280 \\
\hline $\mathbf{Z}$ Factor & --- & 0.8806 & 0.8806 \\
\hline $\boldsymbol{\sigma}$ & {$[\mathrm{Cs}]$} & 0.2598 & 0.2598 \\
\hline $\mathbf{W}$ & {$[\mathrm{kg} / \mathrm{hr}]$} & $1.789 \mathrm{e}+005$ & $1.789 \mathrm{e}+005$ \\
\hline Phase Fraction [molar Basis] & --- & 1.00 & 1.00 \\
\hline Phase Fraction [vol.asis] & -- & -- & 1.00 \\
\hline
\end{tabular}

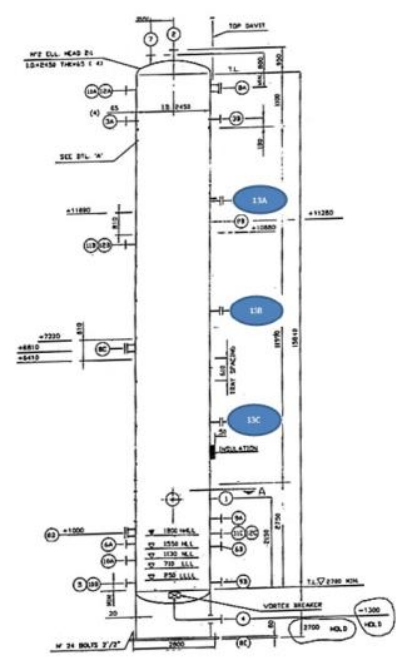

Figure 10: three height of contactor tower.

Also in order to research effect of height (disengagement long) in separation process, from three variety height (13A, 13B and 13C) and gas outlet of contact tower according to figure 10 was sampled so that experimental data shown in table 5 to $8,[18,19]$.

As for tables 5 to 8 , as ever height of sample increases, inversely density decreases so that with decrease density of discrete phases, terminal velocity induces and with increased density of droplets, terminal velocity increases. Also with decrease viscosity of gas, the terminal velocity increases and this is one of separation factors. Table 8 shown that density of outlet gas increase with relation to $13 \mathrm{~A}$ and it means the best height for tower is $13 \mathrm{~A}$ because the least density of gas discharges over there.

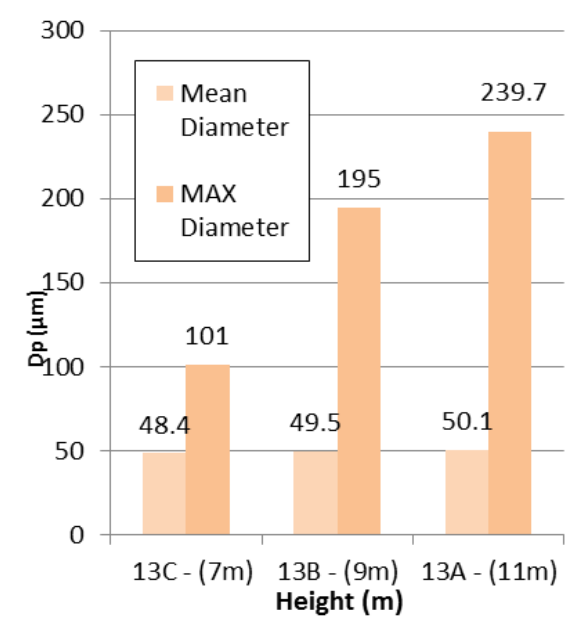

Figure 11: Maximum and mean droplets at three height of contactor tower. 
According to figure 11, simulation results is shown that with increasing height in tower, maximum and mean diameter of droplets grows company with together and as for Eq.6, $\mathrm{K}$ value was increased and separation was improved.

\section{Light Phase}

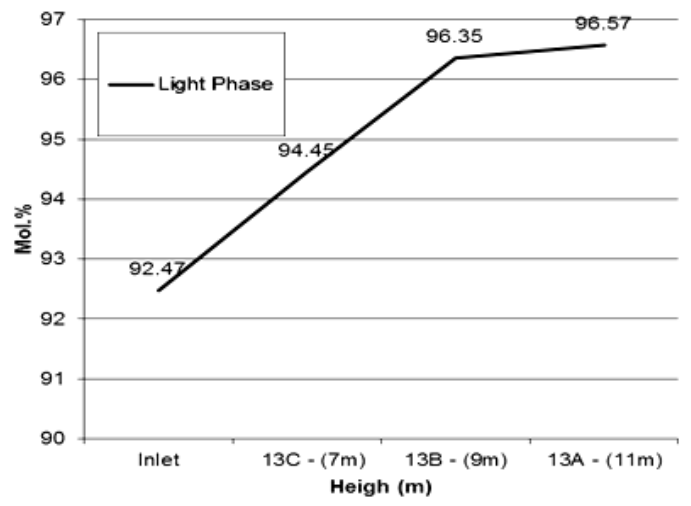

Figure 12: Increasing continues phase in variety height of tower.

In this research, the examination of Amin contactor tower as vertical gas-liquid in order to reduce liquid percent in outlet separation unit and send to dew point setting unit for dehydration was studied. Hence can see, the diverter causes to direct flow to downward of vessel (bottom), increase eddies and steady of them, decrease velocity of droplets toward outlet gas and increase hold up time of droplets in separator and contactor tower. So the effect of growing of particles (droplets) in improving of separation process was researched so that the growing of droplets into separator and tower with 40, 120 and 150 microns was caused increase terminal velocity of droplets and separation factor K either. Also shown that drag force decreases and causes better settling of droplets, in fact, it helps to separation process. The function to gives rise to more compatible with experimental date is $\mathrm{K}$ factor. It is because $\mathrm{K}$ value in TOTAL method that appropriate to relation of particle diameter and drag factor. However, both of parameters are principal function and have the most influence on governing equations, also it is direct influence the terminal velocity. As for the effect of height (disengagement time) in separation process with three height (13A, 13B and 13C) and gas outlet of contact tower, as ever height of sample increases, inversely density decreases so that with decrease density of discrete phases, terminal velocity induces and with increased density of droplets, terminal velocity increases. Also with decrease viscosity of gas, the terminal velocity increases and this is one of separation factors. Hence, as for Eq.6, K factor was increased, therefore, as for aforementioned can say that the important functions on improve separation process are growing of droplets, increasing of height and inlet diverter.

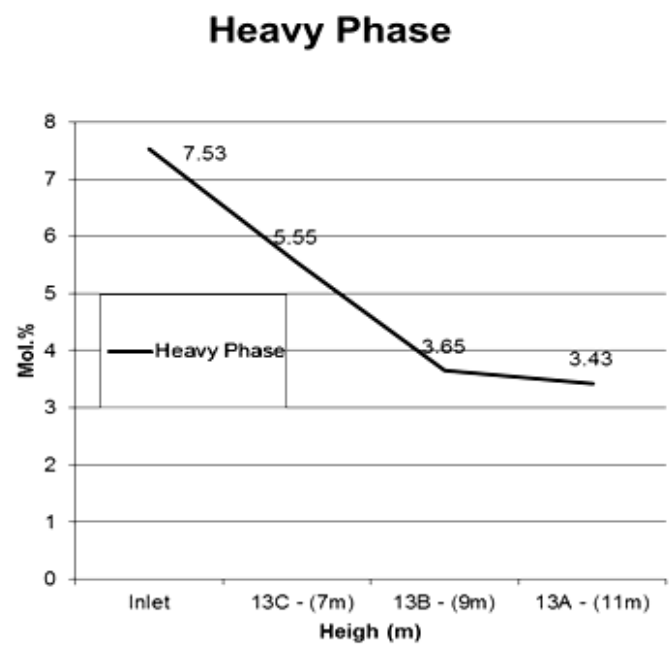

Figure 13: Decreasing discrete phase in variety height of tower

\section{Conclusion}

Additionally according to younger's comment gas-liquid separators can applied in horizontal or vertical status so that he founded if L/D be 1.7 to 3.6, the separators should be used vertically also Branan has proved that if $\mathrm{L} / \mathrm{D}>5$, a horizontal separator should be used. The results of research are shown that in special conditions with $\mathrm{L} / \mathrm{D}>6.5$ can apply vertical separator. Finally experimental data has shown that the settling length can be $36 \mathrm{ft}(11 \mathrm{~m})$ that separation works well and according to Schiman this length should be $0.75 \mathrm{D}$ or a minimum 12 in $(0.305 \mathrm{~m})$ whereas Gerunda recommends a length equal to the diameter or a minimum of 3 $\mathrm{ft}(0.914 \mathrm{~m})$ that present result is new recommendation that as for requirement in similar units can use contactor tower as vertical separator and thereby increase quality inlet of feed to other units and elsewhere.

\section{Acknowledgment}


This research has supported by Sarkhoun and Qeshm Gas Treating Company. Thus, we thanks with all of personnel who assistance us.

\section{References}

Molavi, H. Sanandaji, F. (2009), Design and utilization of Oil, Gas and Petrochemical equipments, Andisheh Sara publication,

IPS-E-PR-880. (1997). Engineering Standard for Process Design of Gas (Vapor)-Liquid Separators.

Razifar, M. (2010). Process design of two and three phase separators in Oil, Gas and Petrochemical industrials, Andisheh Sara publication,

Fluent Soft Ware Manual. V. 6.3.26

Gene E. Kouba. (1996). "CFD Simulation of Single-Phase and Two-Phase Flow in GasLiquid Cylindrical Cyclone Separators." U.S.A., 6-9 October.

M. van Sint Annaland. N.G. Deen, J.A.M. (2005). "Numerical simulation of gas -liquid-solid flows using a combined front tracking and discrete particle method." Kuipers-Faculty of Science and Technology, University of Twente, P.O. Box 217, 7500 AE Enschede, The Netherlands-Received 19 November 2004; received in revised form 16 March 2005; accepted 11 April 2005-Available online 9 June 2005-Chemical Engineering Science 60 (2005) $6188-6198$

Z. Guoyan. (2007)."Numerical Simulation and Experimental Study on the Performance of Gas /liquid Spiral Separator." School of Mechanical engineering. East China University of Science and Technology, Shanghi, China.

H. Luchang. L. Yuejin, L. He'an. (2007). "Numerical Simulation of Gas Holdup Distribution in a Standard Rushton Stirred Tank Using Discrete Particle Method." College of Chemical Engineering, Xiangtan University, Xiangtan 411105, China- Chin. J. Chem. Eng., 15(6) 808-813

Prof. Dr.-Ing H. Nirschl, Dipl.-Ing. X. Romaní Fernández. (2008)."CFD Simulations to investigate Flow and Particle Behaviour in a Solid Bowl Centrifuge." -Karlsruhe University, Institute for Mechanical Process Engineering, Karlsruhe, Germany-ANSYS Conference \&26th CADFEM Users' -October 22-24, 2008 darmstadtiumwiss enschaft । kongresse, Darmstadt, Germany.

Sandra C.K. De Schepper. Geraldine J. Heynderickx. Guy B. (2008). “CFD modeling of all gas-liquid and vapor-liquid flow regimes predicted by the Baker chart." MarinLaboratori umvoor Petrochemische Techniek, Ghent University, Krijgslaan 281 (S5), B-9000 Ghent, Belgium-Received 11 October 2006; received in revised form 31 May 2007; accepted 4 June 2007-Chemical Engineering Journal 138 (2008) 349-357.

J. Erik OLSEN and Schalk. (2009). “COUPLED DPM AND VOF MODEL FOR ANALYSES OF GAS STIRRED LADLES AT HIGHER GAS RATES."- CLOETE-SINTEF Materials \& Chemistry, 7465 TRONDHEIM, NORWAYSeventh International Conference on CFD in the Minerals and Process Industries-CSIRO, Melbourne, Australia-9-11 December .

A.Harrio, J.Patel. (2010). "CFD Simulation of Two-phase and Three-phase Flows in Internal-loop Airlift Reactors." The topic of this Master's thesis was approved by the departmental council of the Department of Mathematics and Physics on 27th May.

Vinay Mahajan. (2010). “CFD Analysis of Hydrodynamics and Mass Transfer of a GasLiquid Bubble Column." A Project submitted to the National Institute of Technology, Rourkela- In partial fulfillment of the requirements of the degree of Bachelor of Technology (Chemical Engineering)- - Roll No. 10600026- DEPARTMENT OF CHEMICAL ENGINEERING NATIONAL INSTITUTE OF TECHNOLOGY, ROURKELA- ORISSA -769 008, INDIA.

Holger Grosshans. Robert Zoltán Szász1. Laszlo Fuchs 1. (2011)." Full Spray Simulation Coupled Volume of Fluid and Lagrangian Particle Tracking methods." Division of Fluid Mechanics, Lund University, Sweden-ILASS Europe, 24th European Conference on Liquid Atomization and Spray Systems, Estoril, Portugal, September 2011. 
Khorshidi,J. Naderipour,I.(2011)," Design of vertical gas-liquid separator and examination its effective parameters in Sarkhoun \& Qeshm refinery", Journal of Basic and Applied Scientific Research. 2(6)(JBASR-1252(

Gambit Soft Ware Manual. V. 2.1.6

Khorshidi,J. Naderipour,I.(2011), " Simulation of vertical gas-liquid separator and examination its effective parameters in Sarkhoun \& Qeshm refinery", The 3rd Conference of Separation Science Engineering, NO.6049. May2012, Zahedan, Iran.

Sarkhoun and Qeshm Treating Co. (2000)," Bandar Abbas, Iran.

KTI PROJECT 0.5.32934, "Sarkhoun II. NIGCGAS \& LPG Sweetening unit (1000)," in ENG. Dossier \&Mechanical books. 2000, Ch. Section B-VOL.28. Bandar Abbas, IranAkaike, H. (1973). Information theory and an extension of the maximum likelihood principle. Em: Proceedings of the 2nd International Symposium on Information Theory, pp. 267281. 